\title{
Study of the Addition of a Thermoplastic Vulcanizate to a HDPE Composite Highly Filled with Magnesium Hydroxide and Its Effect on the Tensile and Flame Retardant Properties
}

\author{
F. I. Beltrán-Ramírez, ${ }^{1,2}$ L. F. Ramos-deValle $\mathbb{D}^{1},{ }^{1}$ E. Ramírez-Vargas $\mathbb{C}^{1},{ }^{1}$ E. Cabrera-Alvarez, ${ }^{3}$ \\ S. Sánchez-Valdes, ${ }^{1}$ A. Espinoza-Martínez $\mathbb{D}^{\mathbb{D}}{ }^{1}$ J. G. Martínez-Colunga, ${ }^{1}$ F. López-Barajas, ${ }^{1}$ \\ and J. J. Esparza-Claudio ${ }^{2}$ \\ ${ }^{1}$ Centro de Investigación en Química Aplicada (CIQA), Boulevard Enrique Reyna 140, CP-25294 Saltillo, Coah., Mexico \\ ${ }^{2}$ Centro de Innovación Aplicada en Tecnologías Competitivas (CIATEC), Omega 201, CP-37545 León, Gto., Mexico \\ ${ }^{3}$ CONACYT-Centro de Investigación en Química Aplicada (CIQA Monterrey), Av. Alianza Sur 204, CP-66629 Apodaca, \\ Nuevo León, Mexico
}

Correspondence should be addressed to L. F. Ramos-deValle; luis.ramos@ciqa.edu.mx and E. Ramírez-Vargas; eduardo.ramirez@ciqa.edu.mx

Received 19 February 2019; Accepted 28 April 2019; Published 17 October 2019

Academic Editor: Ilaria Armentano

Copyright @ 2019 F. I. Beltrán-Ramírez et al. This is an open access article distributed under the Creative Commons Attribution License, which permits unrestricted use, distribution, and reproduction in any medium, provided the original work is properly cited.

\begin{abstract}
A work was carried out in order to obtain a TPV based on HDPE and EPDM, studying the effect of three different peroxides. The effect of one mono- and two bifunctional peroxides was studied. In general, at equal wt\% of peroxide, the bifunctional peroxides produced greater gel content, higher tensile stress, and higher elongation at break. Thereafter, the work was focused on studying the effect of this TPV, as well as a commercial TPO, on the tensile and flame retardant properties of composites based on blends of HDPE and a thermoplastic elastomer (either TPV or TPO), plus $130 \mathrm{phr}$ of magnesium hydroxide (MH). The composites without the rubbery phase, but with $130 \mathrm{phr}$ of $\mathrm{MH}$, were highly brittle and fragile. The composites with the rubbery phase, on the other hand, (either TPO or TPV), were tougher and presented relatively much higher tensile properties. With regard to flame retardancy, the formulations containing the TPV showed better flame retardancy and passed as V-1 in the UL-94V. With respect to the cone calorimeter, those with TPO or TPV all generated a total of $80 \mathrm{MJ}$ of heat energy. The compositions with TPV, however, generated this amount of heat over a larger period of time, i.e., showing less heat generated per second. In addition, the compositions with TPV presented a markedly lower pHRR, by an average of $15 \%$. Thermogravimetric analysis (TGA) showed that the $\mathrm{MH}$ in the samples with a $40 \mathrm{wt} \%$ rubbery phase starts decomposing at $315^{\circ} \mathrm{C}$. However, as the temperature increases, the MH in the TPV composite apparently decomposes at a slower rate than that in the TPO composite.
\end{abstract}

\section{Introduction}

High-density polyethylene (HDPE) is a highly used polyolefin due to its good all-around properties, among which, chemical resistance, thermal stability, easy processing, and abrasion resistance stand out. Nonetheless, as with many other polymers, HDPE is highly flammable, which may greatly limit its applications, unless this defect is overcome. Fortunately, there are many "flame retardant additives" [1] that transform the pure HDPE into a highly used polymer compound. Currently, the metallic hydroxides are the flame retardant additives for polymers consumed at the greatest volumes, and examples of these include magnesium hydroxide and aluminum hydroxide [2-4]. These metallic hydroxides decompose endothermically, producing the corresponding metallic oxide plus water. These decomposition reactions (the endothermic reaction) absorb heat from the combustion zone, generate an intumescent layer (the metallic oxide) that protects the substrate, and liberate water that absorbs heat $[5,6]$. Of these two hydroxides, magnesium 
hydroxide is the most widely used because it decomposes at a higher temperature, withstanding the polyolefin processing temperatures and remaining intact in the final composite [7-9]. However, in order to attain an acceptable flame-retarding effect, very high $\mathrm{MH}$ contents have to be used. The result would be a polymer composite with high flame-retarding characteristics, but fragile and very poor mechanical properties.

In order to overcome or minimize those negative effects, an alternative has been to use coupling agents (such as silanes or titanates $[10,11]$ ) or compatibilizing agents (such as maleic anhydride-grafted polyethylene or polypropylene (PEgMA, PPgMA) [12-14]), which promote a much better interaction/adhesion between a polymer and a filler. Another alternative to minimize the fragility of the highly filled compound is the inclusion of an elastomeric compound that is compatible with the base polymer, such as a thermoplastic olefin (TPO) or a thermoplastic vulcanizate (TPV), both being different types of thermoplastic elastomers (TPE). TPVs roughly consist of thoroughly well-mixed vulcanized rubber particles within a thermoplastic matrix [15]. A variety of vulcanization agents can be used for the preparation of these TPVs, such as phenolic resins [16], sulfur [17], and peroxides [18]. Peroxide crosslinking renders vulcanizates with greater bond strength, which reflects itself in certain final properties, such as greater ageing resistance and lesser compression set at higher temperatures, with the advantage of being a simpler formulation.

In this sense, it has been reported that the flame retardancy of rubber compounds, as measured by the LOI technique, increases linearly with the crosslinking degree of the rubber phase [19].

The objectives of this work were, firstly, to obtain a TPV, studying the effect of three different peroxides, and secondly, to study the effect of the selected TPV on the tensile properties and flame retardancy of a composite based on HDPE, magnesium hydroxide, and the selected TPV.

\section{Experimental}

2.1. Materials. Materials used included a high-density polyethylene (HDPE) from LyondellBasell, Petrothene LM600700, with an MFI of $0.80 \mathrm{~g} / 10 \mathrm{~min}$ and a density of $0.96 \mathrm{~g} / \mathrm{cm}^{3}$; a maleic anhydride-grafted polyethylene (PEgMA) from Dow Chemical; Fusabond E226, used as compatibilizer, with $2 \mathrm{wt} \%$ of maleic anhydride and an MFI of $1.75 \mathrm{~g} / 10 \mathrm{~min}$; and a thermoplastic polyolefin (TPO), Hifax $^{\mathrm{TM}}$ CA 10 A from LyondellBasell, with an MFI of $0.6 \mathrm{~g} / 10 \mathrm{~min}$ and a density of $0.80 \mathrm{~g} / \mathrm{cm}^{3}$, taken as reference for the prepared TPV.

A thermoplastic vulcanizate (TPV), synthetized in our laboratory, based on EPDM and HDPE blends, was also used. The EPDM used was Nordel ${ }^{\mathrm{TM}}$ IP 4770P, from Dow Chemical, with $5 \mathrm{wt} \%$ of ethylidene norbornene (ENB) and $70 \mathrm{wt} \%$ of ethylene. The HDPE used for the TPV synthesis was the same as that mentioned above. The TPV was obtained from a dynamically vulcanized EPDM in a HDPE matrix, studying three different peroxides: Luperox 101 (L) from Arkema, Perkadox 14 (P) from Akzo Nobel, and DCP (D) from
TABle 1: General characteristics of the peroxides studied for the development of the TPV.

\begin{tabular}{lccc}
\hline $\begin{array}{l}\text { Chemical } \\
\text { acronym }\end{array}$ & $\begin{array}{c}\text { Active oxygen } \\
\text { (\%) approx. }\end{array}$ & $t_{1 / 2}=6 \mathrm{~min}^{*}$ & $E_{a}(\mathrm{kcal} / \mathrm{mol})$ \\
\hline DTBPH (L) & 11.0 & $156^{\circ} \mathrm{C}$ & $155.5 \mathrm{~kJ} / \mathrm{mol}$ \\
DTBPIB (P) & 9.5 & $156^{\circ} \mathrm{C}$ & $152.7 \mathrm{~kJ} / \mathrm{mol}$ \\
DCP (D) & 6.0 & $153^{\circ} \mathrm{C}$ & $152.7 \mathrm{~kJ} / \mathrm{mol}$ \\
\hline
\end{tabular}

${ }^{*}$ Temperature at which the half-life time was $6 \mathrm{~min}$.

Sigma-Aldrich, whose characteristics are presented in Tables 1 and 2.

Finally, micrometric magnesium hydroxide $(\mathrm{MH})$ from Albemarle, with an average particle size of $1.0 \mu \mathrm{m}$; nanometric $\mathrm{MH}$ from Nanostructured \& Amorphous Materials Inc., with an average particle size of $20 \mathrm{~nm}$; and silicon oil (Wacker AK 1000) as lubricant, were also used.

\subsection{Preparation of TPVs and Composites}

(a) The TPVs studied in this work were prepared in a Brabender mixing chamber, using roller-type rotors. The following procedure was used: with the mixing chamber at $180^{\circ} \mathrm{C}$ and its rotors rotating at $60 \mathrm{rpm}$, EPDM and HDPE (60/40 wt\%, respectively), were added into the mixing chamber and mixed for $5 \mathrm{~min}$. At this point, the peroxide was added and the mixing continued for another $7 \mathrm{~min}$. at which point, the mix (the TPV) was extracted.

(b) For the preparation of the flame retardant composites, the compositions in Table 3 were first dry blended in a Henschel intensive mixer for $10 \mathrm{~min}$ at $50^{\circ} \mathrm{C}$ and at $1000 \mathrm{rpm}$.

Thereafter, the dry blends were processed in a Werner and Pfleiderer ZSK-30 corotating twin-screw extruder with an $L / D$ ratio of $29: 1$ and $D$ of $30 \mathrm{~mm}$, at $200^{\circ} \mathrm{C}$ and $150 \mathrm{rpm}$ and pelletized [20]. The pelletized nanocomposites were dried at $75^{\circ} \mathrm{C}$ for 12 hours and then injection-molded at $220^{\circ} \mathrm{C}$ into type IV test specimens for tensile and flame retardant properties.

In addition, each composite was compression molded at $185^{\circ} \mathrm{C}$ to obtain $100 \times 100 \times 3 \mathrm{~mm}$ laminates, from which test specimens were cut for flammability tests via a cone calorimeter. The purpose was to compare the effect of two thermoplastic elastomers (TPO vs. TPV) on the tensile and flame retardant properties of the final composite. It is important to mention that the ratio of the micrometric to nanometric $\mathrm{MH}$ was defined from previous work [21].

\subsection{Characterization of TPVs and Composites}

2.3.1. Gel Content \%. For the determination of the gel content of the studied TPVs, $\sim 0.3 \mathrm{~g}$ samples of each formulation were put in xylene for Soxhlet extraction at the xylene boiling temperature for $8 \mathrm{~h}$. Thereafter, each extracted sample was placed in a vacuum oven at $150^{\circ} \mathrm{C}$ for $12 \mathrm{~h}$. Finally, samples were put into a desiccator for $30 \mathrm{~min}$, and then weighed. This was 
TABLE 2: Chemical structure and commercial name of the peroxides studied.

\begin{tabular}{ll}
\hline Chemical/commercial name/supplier & Chemical structure \\
2,5-Dimethyl-2,5-di(tert-butylperoxy)hexane \\
(DTBPH)/Luperox 101/from Arkema
\end{tabular}

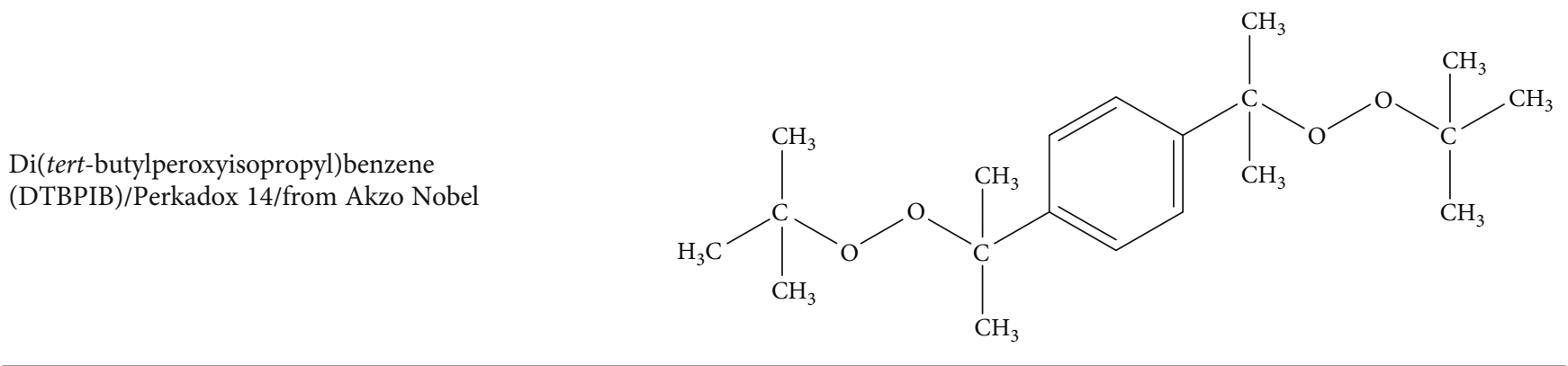<smiles>CC(C)(OOC(C)(C)c1ccccc1)c1ccccc1</smiles>

Luperox (aliphatic) and Perkadox (aromatic) are both bifunctional. DCP (aromatic) is monofunctional.

done according to ASTM D2765, and the calculations were based on

$$
\text { Gel content }(\%)=\left(1-\frac{m_{2}-m_{3}}{m_{2}-m_{1}}\right) * 100
$$

where $m_{1}$ is the weight of the mesh used to encapsulate the sample, $m_{2}$ is the weight of the mesh plus the original sample, and $m_{3}$ is the weight of the mesh plus the extracted and dried sample.

2.4. Tensile Properties of TPVs and Composites. Tensile stress and elongation at break of TPVs and composites were determined using an MTS Criterion Model 43 tensile testing machine coupled with a $5 \mathrm{kN}$ load cell, at a crosshead speed of $50 \mathrm{~mm} / \mathrm{min}$, in accordance to ASTM D638-14.

2.5. Flammability Properties of TPVs and Composites. The flame retardant properties of all the studied composites were determined using two different methods: (a) using a flammability chamber Ceast CCQ-037 in accordance to UL-94, the Standard for Safety of Flammability of Plastic Materials by the Underwriters Laboratories of the US (horizontal and vertical methods), on $125 \times 13 \times 3 \mathrm{~mm}$ test specimens, previously conditioned for $24 \mathrm{hr}$ at $23^{\circ} \mathrm{C}$ and $50 \% \mathrm{RH}$ and (b) using an FTT (Fire Testing Technology) Dual Cone
TABLe 3: Composition ${ }^{\mathrm{a}}$ of the flame retardant studied composites.

\begin{tabular}{lcccc}
\hline $\begin{array}{l}\text { Designation of } \\
\text { composites }^{\mathrm{b}}\end{array}$ & $\begin{array}{c}\text { HDPE } \\
(\mathrm{wt} \%)\end{array}$ & $\begin{array}{c}\text { PEgMA } \\
\text { (wt\%) }\end{array}$ & $\begin{array}{c}\text { TPO } \\
\text { (wt\%) }\end{array}$ & $\begin{array}{c}\text { TPV } \\
\text { (wt\%) }\end{array}$ \\
\hline TPO-00 & 90 & 10 & - & - \\
TPO-10 & 80 & 10 & 10 & - \\
TPO-20 & 70 & 10 & 20 & - \\
TPO-30 & 60 & 10 & 30 & - \\
TPO-40 & 50 & 10 & 40 & - \\
TPV-00 & 90 & 10 & - & - \\
TPV-10 & 80 & 10 & - & 10 \\
TPV-20 & 70 & 10 & - & 20 \\
TPV-30 & 60 & 10 & - & 30 \\
TPV-40 & 50 & 10 & - & 40 \\
\hline
\end{tabular}

${ }^{\mathrm{a}}$ The concentration of HDPE, PEgMA, and TPO/TPV is in wt $\%$, totaling $100 \mathrm{~g}$ in each case. The content of the lubricant and $\mathrm{Mg}(\mathrm{OH})_{2}$ is in $\mathrm{phr}^{\mathrm{c}}$ with respect to the above total $100 \mathrm{~g}$ of resin. In addition to HDPE, PEgMA, and TPO/TPV, all formulations included $1.5 \mathrm{phr}$ of silicon lubricant and $65 \mathrm{phr}$ of micro- and $65 \mathrm{phr}$ of nanomagnesium hydroxides (130 total). ${ }^{\mathrm{b}}$ The TPV used in all composites in this table is a blend of EPDM/HDPE (60/40 wt\%), crosslinked with $0.10 \mathrm{phr}$ Luperox. ${ }^{c}$ phr: parts per hundred parts of resin (parts by weight). 


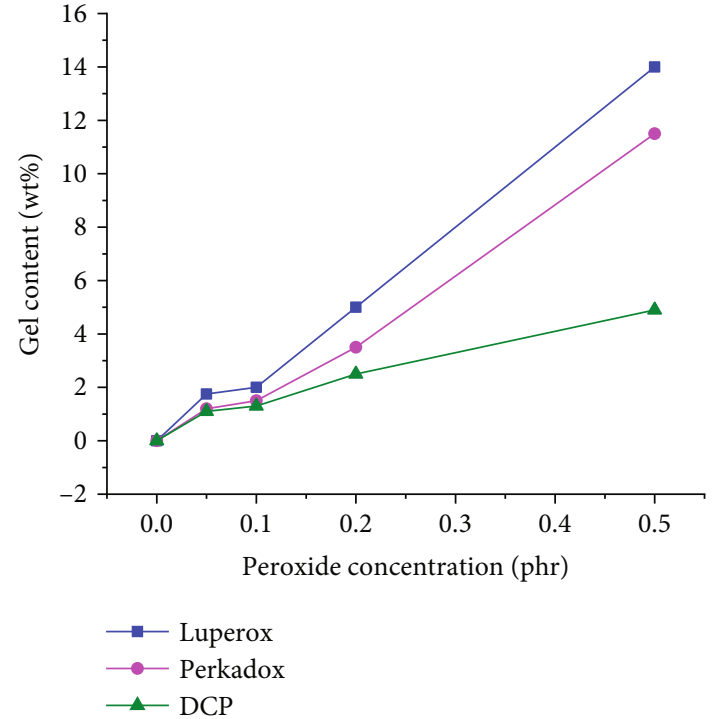

FIGURE 1: Gel content (wt\%) vs. peroxide concentration (phr) of the TPVs studied. The peroxide concentrations in Figures 1, 2, and 3 refer to "phrs" of pure peroxide.

Calorimeter in accordance to ASTM E1354-14 on $100 \times 100$ $\times 3 \mathrm{~mm}$ test specimens, previously conditioned for $24 \mathrm{hr}$ at $23^{\circ} \mathrm{C}$ and $50 \% \mathrm{RH}$. During the cone calorimeter testing, the heat flow upon the sample surface area of $100 \mathrm{~cm}^{2}$ was $35(\mathrm{~kJ} / \mathrm{s}) / \mathrm{m}^{2}$, maintaining a $25 \mathrm{~mm}$ separation between the cone and the sample.

2.6. Thermal Analysis of TPVs and Composites. To examine the thermal stability of the composites, thermogravimetric analyses (TGA) were performed in a TA Instruments Q500 between 0 and $600^{\circ} \mathrm{C}$, using a heating rate of $10^{\circ} \mathrm{C} / \mathrm{min}$, under a nitrogen flow of $50 \mathrm{~mL} / \mathrm{min}$.

2.7. Morphology of Composites. Morphology and particle dispersion analyses were carried out with a JEOL JSM-7401 scanning electron microscope in transmission mode (STEM), on fractured and Au-Pd-coated samples from the previously obtained laminates. All samples were fractured at liquid nitrogen temperature. All micrographs were taken in COMPO mode in order to differentiate between the polymer and the filler.

\section{Results and Discussion}

3.1. Gel Content of TPVs. Figure 1 presents the gel content attained by the EPDM/HDPE TPVs prepared with the three different peroxides, each at four different concentrations. First, it is observed that the gel content increases with the peroxide concentration, and also, that the bifunctional peroxides (Luperox and Perkadox) produce greater gel content than the monofunctional peroxide (DCP), i.e., a greater crosslinking degree, at all studied concentrations.

Luperox and Perkadox decompose producing terbutoxi radicals, which in time generate methyl radicals and other products; these methyl radicals are sufficiently reactive as to



FIgURE 2: Maximum tensile stress at each peroxide concentration vs. peroxide concentration of the TPVs studied.

abstract hydrogen atoms, starting the vulcanization process. In the case of Luperox and Perkadox, however, the relative abundance of methane and terbutanol will boost the ability of the peroxide for hydrogen abstraction.

The slight difference in gelling between Luperox and Perkadox is assumed to be because of the slightly greater active oxygen content of Luperox plus its aliphatic character, which produces radicals with slightly greater mobility, than those of the aromatic Perkadox.

3.2. Tensile Properties of TPVs. Figure 2 presents the tensile stress of the different TPVs, as a function of the peroxide concentration for the three peroxides studied. TPO is the reference material, and the blanc is the 60/40 EPDM/HDPE blend, without crosslinking.

The reference TPO and the blanc presented a tensile stress of 12 and $9 \mathrm{MPa}$, respectively.

It is observed here that the Luperox and Perkadox TPVs presented a maximum tensile stress at about $0.10 \mathrm{phr}$ of peroxide, reaching tensile stresses between 14 and $18 \mathrm{MPa}$. The DCP TPV, on the other hand, barely reached a tensile stress of $7.5 \mathrm{MPa}$ at $0.10 \mathrm{phr}$ peroxide content. In this case, however, the tensile stress increased constantly up to a value of $9 \mathrm{MPa}$ at $0.50 \mathrm{phr} \mathrm{DCP}$.

The observed difference between the Luperox and Perkadox TPVs, versus the DCP TPV, on the other hand, is assumed to be due to the bifunctionality of Luperox and Perkadox versus the monofunctionality of DCP. Additionally, Luperox and Perkadox have higher active oxygen content than DCP.

Figure 3 shows that the Luperox and Perkadox TPVs present the higher elongation at break, around $700 \%$, at a peroxide concentration of $0.10 \mathrm{phr}$, which decreases down to around $500 \%$ at the peroxide concentration of $0.50 \mathrm{phr}$. The DCP TPV, on the other hand, presented the lowest elongations at break, between 250 and $350 \%$ at the four peroxide 




FIGURE 3: Elongation at break at each peroxide concentration vs. peroxide concentration of the TPVs studied.

TABLE 4: Tensile properties of the studied composites, with varying TPO/TPV contents.

\begin{tabular}{lccccc}
\hline & \multicolumn{5}{c}{ Tensile properties (TS tensile stress) } \\
Composites & $\begin{array}{c}\text { TS at } \\
\text { yield } \\
(\mathrm{MPa})\end{array}$ & $\begin{array}{c}\text { TS at } \\
\text { break } \\
(\mathrm{MPa})\end{array}$ & $\begin{array}{c}\text { Elongation } \\
\text { at yield (\%) }\end{array}$ & $\begin{array}{c}\text { Elongation } \\
\text { at break } \\
(\%)\end{array}$ & $\begin{array}{c}\text { Modulus } \\
(\mathrm{MPa})\end{array}$ \\
\hline Pure HDPE & 8.4 & 26.2 & 78 & 540 & 496 \\
Pure TPO & 7.8 & 12.1 & 230 & 610 & 105 \\
Pure TPV & 12.8 & 16.2 & 248 & 750 & 200 \\
TPO-00 & 14.0 & 14.5 & 28 & 30 & - \\
TPO-10 & 18.2 & 24.3 & 120 & 155 & 1580 \\
TPO-20 & 19.5 & 26.2 & 280 & 320 & 1250 \\
TPO-30 & 20.4 & 24.2 & 305 & 330 & 1090 \\
TPO-40 & 20.8 & 26.5 & 300 & 340 & 1135 \\
TPV-00 & 14.0 & 15.0 & 30 & 35 & - \\
TPV-10 & 19.2 & 26.4 & 110 & 130 & 1560 \\
TPV-20 & 19.5 & 23.8 & 270 & 290 & 1150 \\
TPV-30 & 21.4 & 25.4 & 275 & 305 & 1060 \\
TPV-40 & 22.8 & 26.2 & 290 & 335 & 1080 \\
\hline
\end{tabular}

${ }^{a}$ This pure TPV and the TPV in all composites are a blend of EPDM/HDPE, (60/40 wt\%), crosslinked with $0.10 \mathrm{phr}$ Luperox. All 10 composites have 0 to $40 \mathrm{wt} \% \mathrm{TPO} / \mathrm{TPV}$ and $130 \mathrm{phr} \mathrm{Mg}(\mathrm{OH})_{2}$ as in Table 3.

concentrations studied. The reference TPO presented an elongation at break of $600 \%$.

In general, stress and elongation increased with the crosslinking degree, up to the maximum, but upon increasing the crosslinking, the tensile properties tend to decrease, as has been reported for other TPVs [22].

After the above results, the TPV selected for use in all flame retardant composites was the one prepared with EPDM/HDPE 60/40, crosslinked with $0.10 \mathrm{phr}$ of Luperox.

3.3. Tensile Properties of Composites. Table 4 presents the tensile properties of the studied composites. In this sense, it
TABLE 5: Flame resistance of the studied composites, with varying $\mathrm{TPO} / \mathrm{TPV}$ contents.

\begin{tabular}{lcc}
\hline \multirow{2}{*}{ Composites } & \multicolumn{2}{c}{ Flame resistance } \\
& UL-94 HB (horizontal) & UL-94 V (vertical) \\
\hline Pure HDPE & $32.4^{\mathrm{a}}$ & Fails, drips \\
Pure TPO & 27.6 & Fails, drips \\
Pure TPV & 18.6 & Fails, drips \\
TPO-10 & AE & Fails, drips \\
TPO-20 & AE & Fails, drips \\
TPO-30 & AE & Fails, drips \\
TPO-40 & $A E$ & $V-1$ \\
TPV-10 & AE & Fails, drips \\
TPV-20 & $A E$ & $V-1$ \\
TPV-30 & $A E$ & $V-1$ \\
TPV-40 & $A E$ & $V-1$ \\
\hline
\end{tabular}

${ }^{a}$ Burning rate $(\mathrm{mm} / \mathrm{min})$; applicable to the first 3 pure polymers, which burned completely. ${ }^{\mathrm{b}}$ Autoextinguishable; 8 composites with TPO/TPV with $130 \mathrm{phr} \mathrm{Mg}(\mathrm{OH})_{2}$ as in Table $3 .{ }^{\circ}$ This pure TPV and the TPV in all composites are a blend of EPDM/HDPE (60/40 wt\%), crosslinked with $0.10 \mathrm{phr}$ Luperox.

is observed that with respect to the pure polymers, the HDPE shows the highest modulus, whereas the two thermoplastic rubbers present the higher elongation at break. The composites with all the constituents (including the $130 \mathrm{phr}$ of $\left.\mathrm{Mg}(\mathrm{OH})_{2}\right)$, on the other hand, present a relatively similar tensile stress among them, i.e., of $25 \pm 1.5$ $\mathrm{MPa}$, but present an elongation at break that increases with the TPO/TPV content from 30 to $340 \%$, and a modulus that decreases with the TPO/TPV content from 1580 to $1060 \mathrm{MPa}$. This is clearly due to the addition of the softer rubber phase.

As expected, the inclusion of the rubbery TPV or TPO, along with the large amount of flame retardant magnesium hydroxide, resulted in flame-retarded composites with much better tensile properties, sufficient for applications such as cable sheathing.

3.4. Flame Resistance of TPVs and Composites. With respect to flame resistance, Table 5 shows that (a) all compositions passed the UL-94-HB standard (horizontal) as autoextinguishable (AE), that is, the samples were subjected to a Bunsen burner flame for 30 seconds and the samples lighted, but after removing the Bunsen flame, the flame was extinguished; (b) only four compositions passed the UL-94-V (vertical) as V1, the one with $40 \mathrm{phr}$ TPO and those with 20, 30, and $40 \mathrm{phr}$ TPV; all others failed, showing a slight to intense dripping.

The pure polymers HDPE, TPO, and TPV, on the other hand, were consumed completely, at different burning rates, TPV being the one with clearly the slowest burning rate. In conclusion, TPV presents the best flame retardant characteristic among the three pure polymers (HDPE, TPO, and TPV), which is assumed to be due to the partly crosslinked structure of the TPV, as determined in other studies $[19,23]$.

Figure 4 shows that the time for the extinction of the flame decreases as the TPO/TPV content increases; it also 


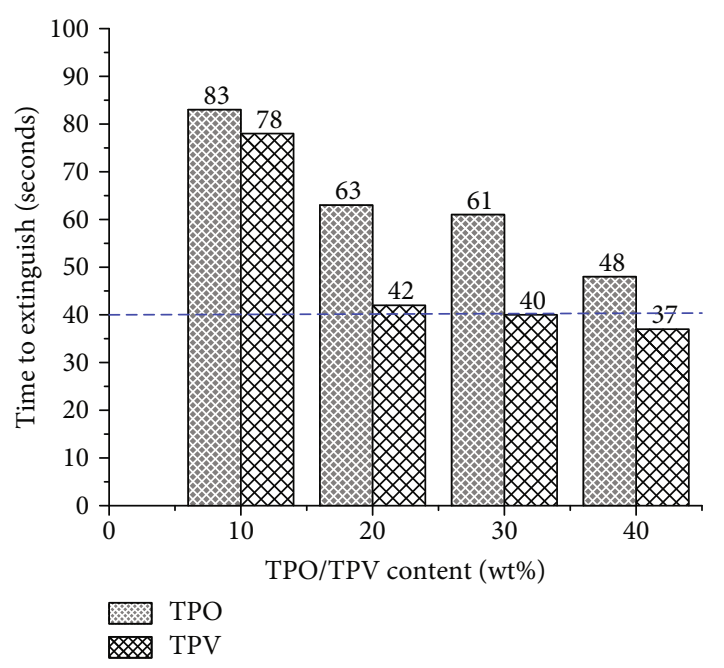

FIGURE 4: Time to self-extinction of the flame during the UL-94 HB test of the TPO and TPV composites studied. Formulation of all composites is the same as in Table 3.

shows that the compositions with TPV present the shortest times for the extinction of the flame, which indicates a better flame resistance than those with TPO. One reason could simply be because the pure TPV presents a better flame resistance than the pure TPO. This better flame resistance of crosslinked polymer structures has been reported elsewhere $[24,25]$. This effect is assumed to be because the splitting of a crosslinked chain generates much less volatile compounds than a linear chain, as well as because a crosslinked chain generates more insulating residual char.

Apart from the UL-94 flammability tests, the cone calorimeter was also used to assess the flammability of the studied composites. Using this technique, the heat release rate (HRR), the amount of heat liberated at the peak of the heat release rate (pHRR), the time to ignition, once subjected to a flame $\left(t_{i}\right)$, the time to reach the $\mathrm{pHRR}\left(t_{\mathrm{pHRR}}\right)$, the total heat released from ignition to extinction of the flame (THR), and the total time of fire, from ignition to extinction $\left(t_{f}\right)$ can be determined. It has been estimated that HRR is one of the most important parameters for safety in the evaluation of fires [26-28].

Compositions with $10 \mathrm{phr}$ TPO/TPV were not included in the cone calorimeter tests. These had shown very low flame resistance in the UL-94 testing.

Figure 5 and Table 6 show the variation of HRR with time as obtained from the cone calorimeter. It is observed that, as in the case of the UL-94, there is a difference in the flame retardant properties of the composites that apparently, clearly arise solely due to the use of either TPO or TPV. First, it is observed that each of the six composites studied (the three with TPO and the three with TPV) generated a total of approximately $80 \mathrm{MJ}$ of heat energy (that is, 19.1 million calories); second, the composites with TPV generated these large amount of heat energy, but in a larger period of time $\left(t_{i}-t_{f}\right)$, showing less heat generated per second, producing a less strong fire with the corresponding smaller increases in

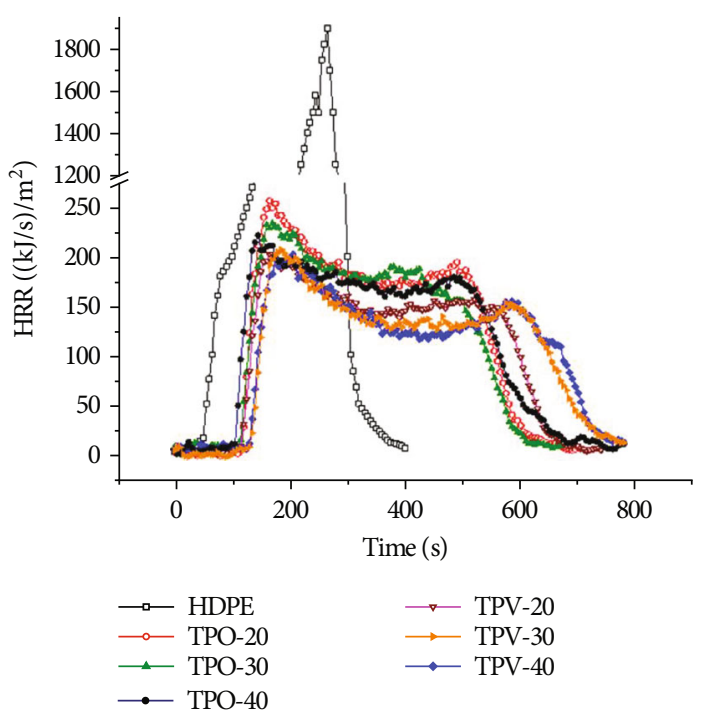

FIGURE 5: Variation of the heat release rate (HRR) versus time for the composites studied, with TPO and TPV contents of 20,30, and $40 \mathrm{phr}$, and for HDPE.

TABle 6: Data obtained from the cone calorimeter on the composites studied.

\begin{tabular}{lccccc}
\hline Formulations $^{\mathrm{a}}$ & $\begin{array}{c}t_{i} \\
(\mathrm{~s})\end{array}$ & $\begin{array}{c}t_{\mathrm{pHRR}} \\
(\mathrm{s})\end{array}$ & $\begin{array}{c}\mathrm{pHRR} \\
(\mathrm{kJ} / \mathrm{s}) / \mathrm{m}^{2}\end{array}$ & $\begin{array}{c}\mathrm{THR} \\
\left(\mathrm{MJ} / \mathrm{m}^{2}\right)\end{array}$ & $\begin{array}{c}t_{f} \\
(\mathrm{~s})\end{array}$ \\
\hline HDPE & 43 & 148 & 1,924 & 148.4 & 414 \\
TPO-20 & 113 & 165 & 257 & 84.1 & 618 \\
TPO-30 & 110 & 170 & 244 & 78.2 & 626 \\
TPO-40 & 111 & 165 & 218 & 78.6 & 655 \\
TPV-20 & 122 & 205 & 202 & 80.7 & 730 \\
TPV-30 & 116 & 201 & 208 & 80.5 & 734 \\
TPV-40 & 128 & 190 & 207 & 79.5 & 810 \\
\hline
\end{tabular}

${ }^{a}$ The TPV in all composites is a blend of EPDM/HDPE (60/40 wt\%), crosslinked with $0.10 \mathrm{phr}$ Luperox. All 6 composites with TPO/TPV and with $130 \mathrm{phr} \mathrm{Mg}(\mathrm{OH})_{2}$ as in Table $3.1 \mathrm{~W}=1 \mathrm{~J} / \mathrm{s}$ ( 1 watt of power produces 1 Joule/s or 0.24 calories/s of heat energy).

temperature, as compared with those with TPO; third, the composites with TPV presented a markedly lower pHRR, by an average of $15 \%$, even though all have the same $\mathrm{Mg}(\mathrm{OH})_{2}$ content. Considering the above results, the composites with TPV show the better flame resistance characteristics.

The pHRR of HDPE, which is included as a comparison in Figure 5, resulted to be around $1924(\mathrm{~kJ}) / \mathrm{m}^{2}$, which coincides with the reported values $[21,29]$, whereas the pHRR of the studied composites with TPV and with $\mathrm{Mg}(\mathrm{OH})_{2}$ resulted at around $200(\mathrm{~kJ} / \mathrm{s}) / \mathrm{m}^{2}$, that is, $9-10$ times lower.

3.5. Thermal Analysis of Composites. Figure 6 presents a thermogravimetric analysis of the pure nano- and micro- $\mathrm{MH}$, a 50/50 blend of HDPE/EPDM, and two of the composites studied (with either $40 \mathrm{wt} \%$ TPO or $40 \mathrm{wt} \% \mathrm{TPV}$ ). 


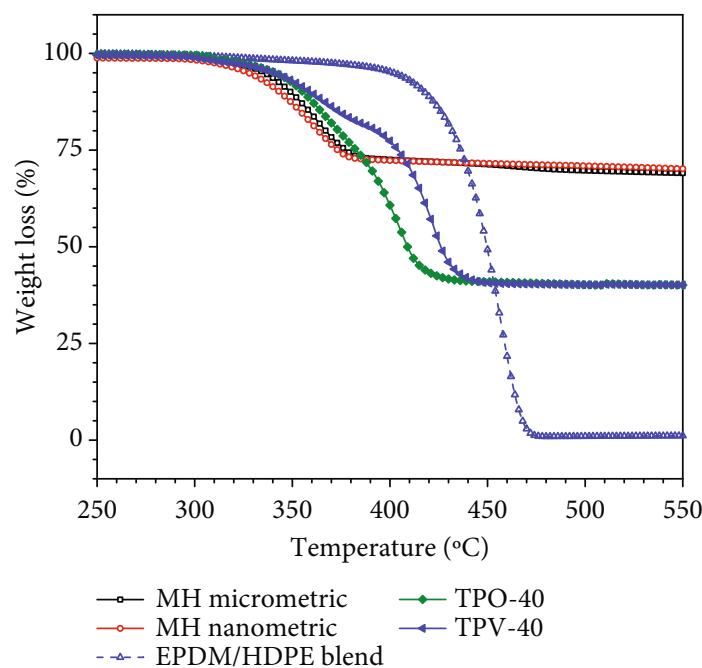

FIgURE 6: Thermogravimetric analysis of nano- and micropure $\mathrm{Mg}(\mathrm{OH})_{2}$, the 50/50 EPDM/HDPE blend, and two of the composites studied, with $40 \mathrm{wt} \%$ of TPO or TPV.

First, Figure 6 shows that the two magnesium hydroxides (micro- and nanosized) follow roughly the same curve, the hydroxide decomposition and the water evaporation starting at about $315^{\circ} \mathrm{C}$ and ending up at about $380^{\circ} \mathrm{C}$; however, at some points along this decomposition process, it appears that the nano- $\mathrm{MH}$ decomposes about $4-5^{\circ} \mathrm{C}$ sooner, which can be attributed to the higher surface area per unit weight of the nano-MH which is subjected to the heat source. In both cases, the residue is around 69\%, which would correspond to $\mathrm{MgO}$.

$$
\begin{array}{cc}
\mathrm{Mg}(\mathrm{OH})_{2} & \stackrel{\Delta}{\rightarrow} \mathrm{MgO}+\mathrm{H}_{2} \mathrm{O} \uparrow \\
58 \mathrm{~g} & 40 \mathrm{~g}+18 \mathrm{~g} \\
100 \mathrm{wt} \% & 69 \%+31 \%
\end{array}
$$

Second, it shows that the blanc (the 60/40 EPDM/HDPE blend) starts decomposing and evaporating at $\sim 405^{\circ} \mathrm{C}$ and is totally consumed at around $470^{\circ} \mathrm{C}$, leaving only traces of residue. This behavior is in accordance with what has been previously reported, since both polymers have almost the same thermal stability [30].

Third, it shows the TPO and the TPV composites studied; on the other hand, each shows two apparent decompositio$\mathrm{n} /$ evaporation steps. The first one would correspond to the decomposition of $\mathrm{MH}$ and the evaporation of the resulting water, whereas the second one would correspond to the decomposition and evaporation of the polymeric part. The first step occurs at clearly different rates for each of the two different composites, both starting at about $325^{\circ} \mathrm{C}$; however, in the case of TPO, it ends up at $385^{\circ} \mathrm{C}$, whereas in the case of TPV, it ends up at $400^{\circ} \mathrm{C}$.

During the first step, there are certain differences among these two composites, which arise from the different "decomposition rates." The weight loss occurs at a slower rate in the TPV composite, producing a phase shift of $15^{\circ} \mathrm{C}$ between the TPV and the TPO composites by the end of this first decomposition/evaporation step. It appears that the $\mathrm{Mg}(\mathrm{OH})_{2}$ in the TPV composite decomposes at a slower rate. The second decomposition/evaporation step, on the other hand, occurs at the same rate in both composites, ending up with the same phase shift of $15^{\circ} \mathrm{C}$ (the $\mathrm{TPO}$ at $415^{\circ} \mathrm{C}$ and the TPV at $430^{\circ} \mathrm{C}$ ).

This difference between the two composites can be attributed to the TPV, which contains a slightly crosslinked phase, and as has been reported, crosslinking produces carbon rich polymer chains which results in char formation, increasing its thermal stability [19]. This is very important in the thermal decomposition rate because char can act as a barrier between the polymer surface and the volatile fragments and oxygen in air [31].

Fourth, from the above, it appears that when "pure," the decomposition of $\mathrm{Mg}(\mathrm{OH})_{2}$ and the evaporation of the resulting water start at $315^{\circ} \mathrm{C}$ and end up at $385^{\circ} \mathrm{C}$, whereas in the TPV-40 composite studied, these decomposition and evaporation processes of $\mathrm{Mg}(\mathrm{OH})_{2}$ start at $320^{\circ} \mathrm{C}$ but end up at $400^{\circ} \mathrm{C}$. When heating at $10^{\circ} \mathrm{C} / \mathrm{min}$, there is a lag of approx. $15^{\circ} \mathrm{C}$ in the decomposition/evaporation of $\mathrm{Mg}(\mathrm{OH})_{2}$ when in the composite, as compared to the decomposition/ evaporation of $\mathrm{Mg}(\mathrm{OH})_{2}$ when pure. This is assumed to be due to the slightly higher thermal stability of the crosslinked $\mathrm{TPV}$, which tends to form a char layer that might retard the start of decomposition of the $\mathrm{Mg}(\mathrm{OH})_{2}$.

3.6. Morphology of Composites. Figure 7 presents the SEM micrographs of the composites with the 20 and $40 \mathrm{phr}$ TPO (Figures $7(\mathrm{a})$ and $7(\mathrm{~b})$ ) and the 20 and $40 \mathrm{phr}$ TPV (Figures $7(\mathrm{c})$ and $7(\mathrm{~d})$ ). In all four cases, the characteristic hexagonal micrometric $\mathrm{Mg}(\mathrm{OH})_{2}$ particles can be observed.

In addition, several "hollow spots" can be appreciated in the four micrographs. These are assumed to be left after the sample was fractured for the SEM analysis, due to phase separation. Composites with either TPO or TPV both show these hollow spots.

This is assumed to be because the amount of the compatibilizer used in these composites was a little less than required.

Nonetheless, this diminished amount of compatibilizer was still sufficient to produce the ductile fractures in the composites with 20 and $40 \mathrm{phr}$ of rubbery phase, as observed in the micrographs in Figures 7(a), 7(b), 7(c), and 7(d). Additionally, this is consistent with the good results obtained on the tensile properties discussed above.

It can also be observed that the formulations with TPV (Figures $7(\mathrm{c})$ and $7(\mathrm{~d})$ ) present a slightly better distribution of the MH than those with TPO (Figures 7(a) and 7(b)). This may have had an influence on the better performance of the formulations with TPV, especially in flame retardant properties (passed as V1 in UL-94-V and presenting a noticeably lower pHRR).

It is worth mentioning that all composites presented agglomerates, though these appear well distributed in the polymer matrix. This agglomeration is clearly due to the very high filler content (130 phr). But, on the other hand, this high filler content is required in order to achieve the desired flame resistant characteristics. 


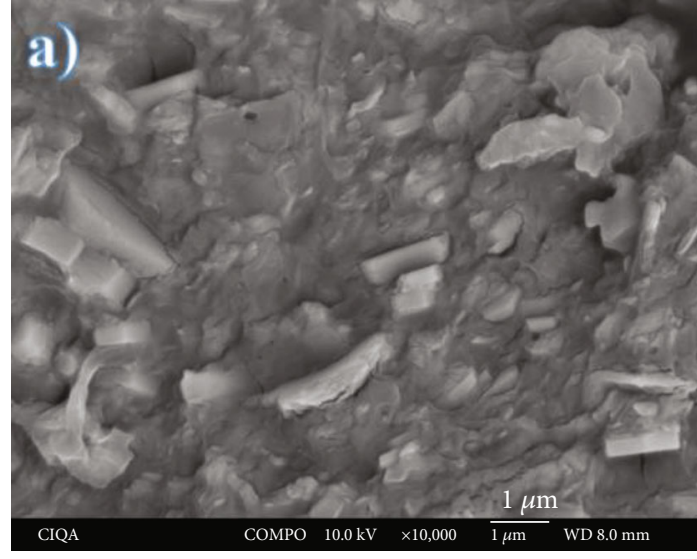

(a)



(c)

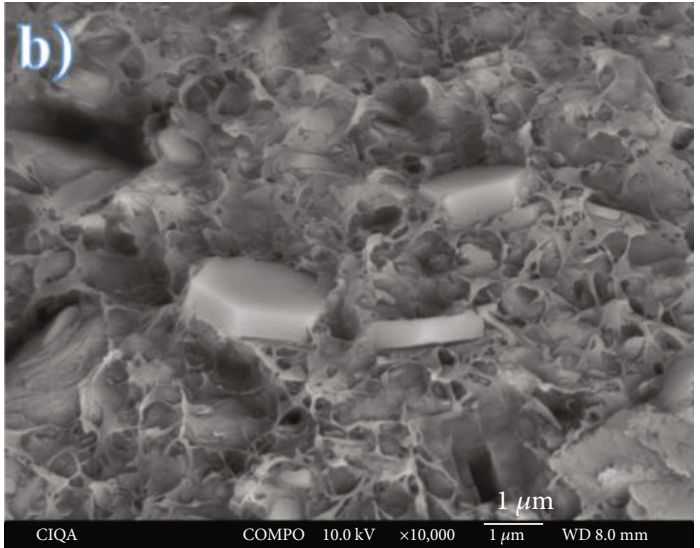

(b)

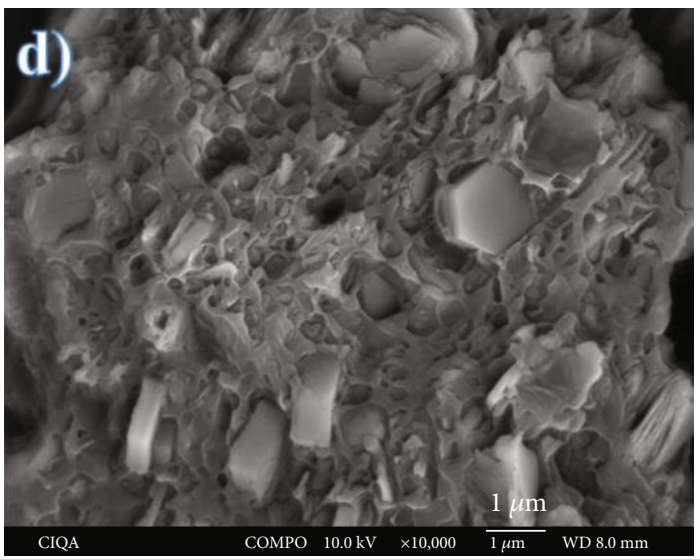

(d)

FIgURE 7: SEM images corresponding to composites (a) TPO-20, (b) TPO-40, (c) TPV-20, and (d) TPV-40.

\section{Conclusions}

With respect to the synthesis of the TPVs, the Luperox peroxide, by being bifunctional and aliphatic (against the monofunctional DCP and the bifunctional but aromatic Perkadox), rendered the TPVs with the highest crosslinking degree, as well as the highest tensile properties. With respect to the flame retardancy, those formulations containing the TPV (versus those containing the TPO) showed a better flame retardancy and passed as $\mathrm{V}-1$. With respect to the cone calorimeter, though all generated the same amount of heat energy (a total of approximately $80 \mathrm{MJ}$ ), the composites with TPV generated this amount of heat over a longer period of time, showing less heat generated per second. In addition, the composites with TPV presented a markedly lower pHRR by an average of $15 \%$. Thermogravimetric analysis (TGA) showed that the MH in the sample with TPV decomposed at a slower rate than the $\mathrm{MH}$ in the sample with TPO or the MH pure. This was attributed to the tendency of the TPV to form a char layer that might retard the start of decomposition of the $\mathrm{Mg}(\mathrm{OH})_{2}$. With respect to the tensile properties, the addition of the rubbery phase transformed the highly brittle composite with $130 \mathrm{phr}$ of magnesium hydroxide into a tough composite with much higher tensile properties, while maintaining its high flame retardancy.

\section{Data Availability}

The data used to support the findings of this study are included within the supplementary information files.

\section{Conflicts of Interest}

The authors declare that they have no conflicts of interest.

\section{Acknowledgments}

One of the authors (F.I. Beltrán-Ramírez) thanks CONACYT for granting her a scholarship to carry her PhD studies. Also, the authors gratefully acknowledge the financial support of CONACYT through projects CB-222805 and LN-232753. The authors also wish to thank Francisco Zendejo, Mario Palacios, Rodrigo Cedillo, Jesus Rodriguez, Luis Enrique Reyes, Alejandro Espinoza, Sergio Zertuche, Adán Herrera, Myriam Lozano, Liliana Naranjo, E. Hurtado-Suarez, and D. Alvarado for their technical and informative support. 


\section{Supplementary Materials}

The files in excel format provide the experimental data obtained during experimentation, from which Figures 1 to 6 were obtained. (Supplementary Materials)

\section{References}

[1] C. Papaspyrides and P. Kiliaris, "Polymer combustion," in Polymer Green Flame Retardants, p. 942, ELSEVIER, 2014.

[2] F. Carpentier, S. Bourbigot, M. Le Bras, R. Delobel, and M. Foulon, "Charring of fire retarded ethylene vinyl acetate copolymer-magnesium hydroxide/zinc borate formulations," Polymer Degradation and Stability, vol. 69, no. 1, pp. 83-92, 2000.

[3] Z. Wang, B. Qu, W. Fan, and P. Huang, "Combustion characteristics of halogen-free flame-retarded polyethylene containing magnesium hydroxide and some synergists," Journal of Applied Polymer Science, vol. 81, no. 1, pp. 206-214, 2001.

[4] Z. Li and B. Qu, "Flammability characterization and synergistic effects of expandable graphite with magnesium hydroxide in halogen-free flame-retardant EVA blends," Polymer Degradation and Stability, vol. 81, no. 3, pp. 401-408, 2003.

[5] K. McGarry, J. Zilberman, T. R. Hull, and W. D. Woolley, "Decomposition and combustion of EVA and LDPE alone and when fire retarded with ATH," Polymer International, vol. 49, no. 10, pp. 1193-1198, 2000.

[6] G. Camino, A. Maffezzoli, M. Braglia, M. De Lazzaro, and M. Zammarano, "Effect of hydroxides and hydroxycarbonate structure on fire retardant effectiveness and mechanical properties in ethylene-vinyl acetate copolymer," Polymer Degradation and Stability, vol. 74 , no. 3, pp. 457-464, 2001.

[7] S.-P. Liu, "Flame retardant and mechanical properties of polyethylene/magnesium hydroxide/montmorillonite nanocomposites," Journal of Industrial and Engineering Chemistry, vol. 20, no. 4, pp. 2401-2408, 2014.

[8] A. Pilarska, K. Bula, K. Myszka et al., "Functional polypropylene composites filled with ultra-fine magnesium hydroxide," Open Chemistry, vol. 13, no. 1, pp. 161-171, 2015.

[9] M. Wang, X.-F. Zeng, J.-Y. Chen, J.-X. Wang, L.-L. Zhang, and J.-F. Chen, "Magnesium hydroxide nanodispersion for polypropylene nanocomposites with high transparency and excellent fire-retardant properties," Polymer Degradation and Stability, vol. 146, no. 327-333, pp. 327-333, 2017.

[10] X. Chen, J. Yu, S. Guo, S. Lu, Z. Luo, and M. He, "Surface modification of magnesium hydroxide and its application in flame retardant polypropylene composites," Journal of Materials Science, vol. 44, no. 5, pp. 1324-1332, 2009.

[11] E. N. Cabrera-Álvarez, L. F. Ramos-deValle, S. Sánchez-Valdes et al., "Study of the silane modification of magnesium hydroxide and their effects on the flame retardant and tensile properties of high density polyethylene nanocomposites," Polymer Composites, vol. 35, no. 6, pp. 1060-1069, 2014.

[12] S. M. B. Nachtigall, M. Miotto, E. E. Schneider, R. S. Mauler, and M. M. Camargo Forte, "Macromolecular coupling agents for flame retardant materials," European Polymer Journal, vol. 42, no. 5, pp. 990-999, 2006.

[13] N. Wang, J. Zhang, Q. Fang, and D. Hui, "Influence of mesoporous fillers with PP-g-MA on flammability and tensile behavior of polypropylene composites," Composites Part B: Engineering, vol. 44, no. 1, pp. 467-471, 2013.
[14] R. Lujan-Acosta, S. Sánchez-Valdes, E. Ramírez-Vargas et al., "Effect of amino alcohol functionalized polyethylene as compatibilizer for LDPE/EVA/clay/flame-retardant nanocomposites," Materials Chemistry and Physics, vol. 146, no. 3, pp. 437-445, 2014.

[15] R. R. Babu and K. Naskar, "Recent developments on thermoplastic elastomers by dynamic vulcanization," in Advanced Rubber Composites. Advances in Polymer Science, vol 239, G. Heinrich, Ed., pp. 219-248, Springer, Berlin, Heidelberg, 2011.

[16] M. D. Stelescu, A. Airinei, C. Grigoras, and I. G. Niculescu-Aron, "Use of differential scanning calorimetry (DSC) in the characterization of EPDM/PP blends," International Journal of Thermophysics, vol. 31, no. 11-12, pp. 2264-2274, 2010.

[17] E. Prut, T. Medintseva, and V. Dreval, "Mechanical and rheological behavior of unvulcanized and dynamically vulcanized i-PP/EPDM blends," Macromolecular Symposia, vol. 233, no. 1, pp. 78-85, 2006.

[18] C. Nakason, K. Nuansomsri, A. Kaesaman, and S. Kiatkamjornwong, "Dynamic vulcanization of natural rubber/high-density polyethylene blends: effect of compatibilization, blend ratio and curing system," Polymer Testing, vol. 25, no. 6, pp. 782-796, 2006.

[19] C.-P. Yang and W.-T. Chen, "Effects of brominated flame retardants and crosslinking agents on the flame retardancy of rubbers," Journal of Applied Polymer Science, vol. 36, no. 4, pp. 963-978, 1988.

[20] A. Walong, A. Kaesaman, T. Sakai, and N. Lopattananon, "Properties of fire retardant TPVs from NR/PP blends filled with aluminium trihydrate and magnesium hydroxide with reference to the effect of mixing methods," Advanced Materials Research, vol. 844, pp. 297-300, 2014.

[21] F. I. Beltrán-Ramírez, L. F. Ramos-deValle, E. Ramírez-Vargas et al., "Effect of nanometric metallic hydroxides on the flame retardant properties of HDPE composites," Journal of Nanomaterials, vol. 2014, Article ID 969184, 11 pages, 2014.

[22] N. Ning, S. Li, H. Wu et al., "Preparation, microstructure, and microstructure-properties relationship of thermoplastic vulcanizates (TPVs): a review," Progress in Polymer Science, vol. 79, pp. 61-97, 2018.

[23] F. Zhao, W. Bi, and S. Zhao, "Influence of crosslink density on mechanical properties of natural rubber vulcanizates," Journal of Macromolecular Science, Part B Physics, vol. 50, no. 7, pp. 1460-1469, 2011.

[24] A. A. Pilarska, Ł. Klapiszewski, and T. Jesionowski, "Recent development in the synthesis, modification and application of $\mathrm{Mg}(\mathrm{OH})_{2}$ and MgO: a review," Powder Technology, vol. 319, pp. 373-407, 2017.

[25] F. Rabbi, Systematic Analysis of Flammability Reduction of Polymer Nano-Composites, MSc Thesis, Bangladesh University of Eng and Technol, 2009.

[26] E. İbibikcan, Use of Boron Compounds as Synergistic Flame Retardant in LDPE-EVA Blends and Nanocomposites, MSc Thesis, Middle East Tech. University, 2013.

[27] H. Huang, M. Tian, L. Liu, Z. He, Z. Chen, and L. Zhang, "Effects of silicon additive as synergists of $\mathrm{Mg}(\mathrm{OH})_{2}$ on the flammability of ethylene vinyl acetate copolymer," Journal of Applied Polymer Science, vol. 99, no. 6, pp. 3203-3209, 2006.

[28] M. Zanetti, G. Camino, R. Thomann, and R. Mülhaupt, "Synthesis and thermal behaviour of layered silicate-EVA 
nanocomposites," Polymer, vol. 42, no. 10, pp. 4501-4507, 2001.

[29] M. Zanetti, T. Kashiwagi, L. Falqui, and G. Camino, "Cone calorimeter combustion and gasification studies of polymer layered silicate nanocomposites," Chemistry of Materials, vol. 14, no. 2, pp. 881-887, 2002.

[30] H. Ismail, P. Pasbakhsh, M. N. A. Fauzi, and A. Abu Bakar, "Morphological, thermal and tensile properties of halloysite nanotubes filled ethylene propylene diene monomer (EPDM) nanocomposites," Polymer Testing, vol. 27, no. 7, pp. 841$850,2008$.

[31] J. Luche, E. Mathis, T. Rogaume, F. Richard, and E. Guillaume, "High-density polyethylene thermal degradation and gaseous compound evolution in a cone calorimeter," Fire Safety Journal, vol. 54, pp. 24-35, 2012. 


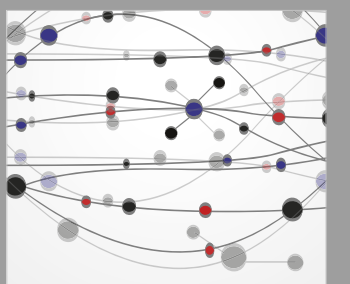

The Scientific World Journal


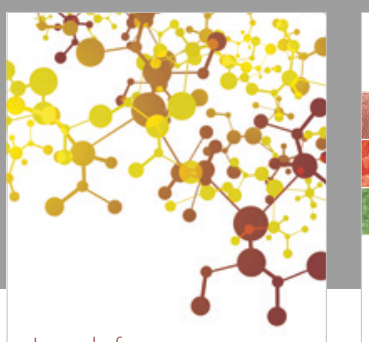

Journal of

Applied Chemistry
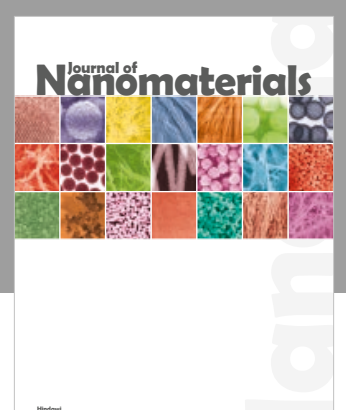

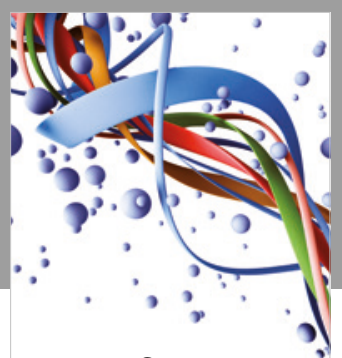

Scientifica



Polymer Science

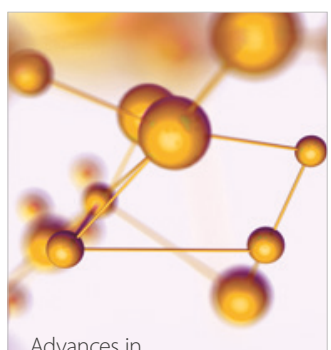

Physical Chemistry
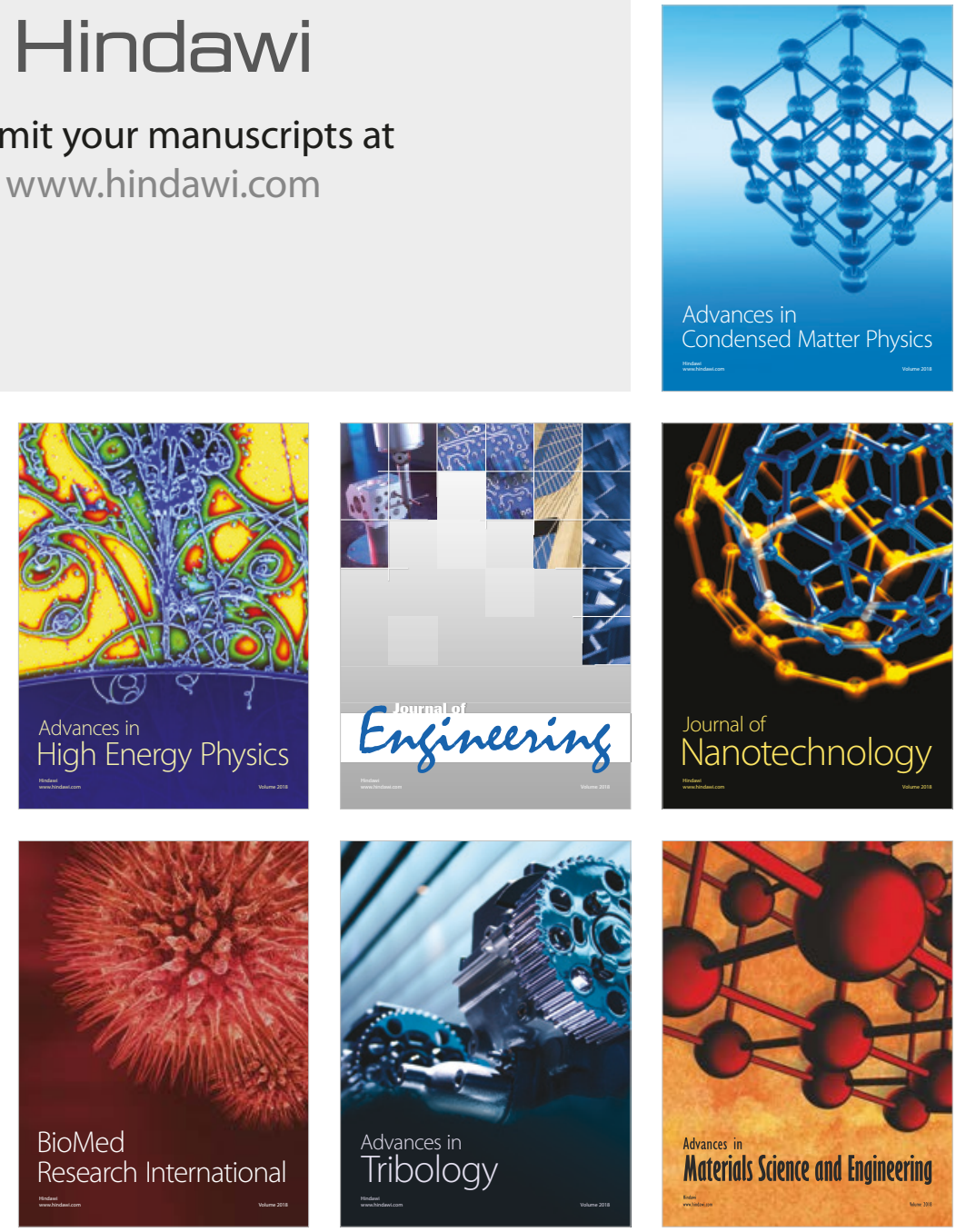